\title{
A questão do hibridismo na relação entre gêneros discursivos e mudança social
}

\author{
Maria Carmen Aires Gomes \\ Universidade Federal de Viçosa
}

\section{Abstract}

This study focuses on hybridization and ambivalence of genres and discourses that emerge in late modernity narratives. The work is based on critical discourse analysis, which views language as a historically marked social activity. The results of the article point to the relation among discourse, genre and social change. 


\section{INTRODUÇÃO}

emergência no contexto histórico de uma ordem social
centrada nas relações de consumo, tecnológicas e burocra-
tizadas resulta numa heterogênea e híbrida constituição de práticas sociais, espaços discursivos, gêneros discursivos e vozes, além de identidades múltiplas e de grupos instáveis de sujeitos posicionados sócio-historicamente.

O objetivo deste artigo é refletir sobre as relações de abertura e criatividade dos gêneros discursivos, com base numa visão de linguagem como prática social; logo, como elemento da mudança na vida social. A questão a ser discutida é como diferentes gêneros discursivos e discursos (categorias constituintes das ordens do discurso, FOUCAULT, 1979) se aproximam em condições sociais particulares para produzirem novos e híbridos gêneros, formando uma superfície acidental e desigual, em função do contexto sócio-histórico em que se inserem. Tais questões serão examinadas pelo viés teórico-metodológico da Análise de Discurso Crítica, principalmente os estudos desenvolvidos por Fairclough (1989, 1992) e Chouliaraki e Fairclough (1999).

\section{CONSIDERAÇÕES SOBRE A TEORIA SOCIAL DO DISCURSO}

Insistindo no fato de que as práticas sociais não são determinadas por relações de causa e efeito, mas de que a linguagem em uso e o exercício do poder se relacionam e se estabelecem de forma opaca, já que constituem modos de ação em interações histórica e socialmente situadas de forma dialética com outras facetas do social, Fairclough (1989, 1992, 1995, 1998) propõe um projeto de Análise de Discurso Crítica, denominado Teoria Social do Discurso (TSD). 
A TSD se propõe a investigar os problemas emergentes da sociedade contemporânea através da esfera pública, por intermédio dos diálogos produzidos por ela. O primeiro pressuposto é constatar a linguagem em uso como prática social, o segundo é ressaltar que as transformações ocorridas no espaço e no tempo acarretam mudanças nos valores, nas crenças, instituições sociais e ordens do discurso de uma sociedade. Figura-se como pesquisa crítica da mudança na vida social contemporânea, através da análise intertextual das ordens do discurso que se projetam, articulam-se e se transformam no curso das lutas hegemônicas de poder. O quadro que emerge nesse contexto é o de tensão, da dialética entre estrutura e ação social e da proliferação de linguagens e vozes.

Enfim, a agenda da TSD é, hoje, especificar as relações de abertura e criatividade dos discursos e gêneros discursivos, sob a visão de linguagem como elemento da mudança na vida social. É através da linguagem que nos posicionamos sócio-historicamente seja em movimentos de resistência, seja de subordinação.

Fairclough (1989, p. 31) considera que "prática social tem uma relação ativa com a realidade, muda a realidade"; logo, ela é bidirecional: estruturas sociais não só realizam as práticas sociais e discursivas, como também são produto delas. Dois teóricos sociais críticos devem ser destacados como suportes da TSD na questão da dialética discursiva: Giddens (1991) e Harvey (1989). Eles discutem uma noção de prática social mais reflexiva, em que os discursos ficam mais propensos às mudanças, já que ordenam e inculcam outros discursos. O fato é que há uma expectativa de mudança em meio a diversas práticas sociodiscursivas hegemônicas.

Harvey (1989) insiste em que as sociedades contemporâneas são dominadas pelo transitório e pelo volátil, ocasionando um apagamento da distância entre as noções de espaço e tempo. Ressalta ainda que a sociedade vive hoje sob a égide de uma cultura da velocidade, da transformação e da aceleração, em que as barreiras espaciais, antes intransponíveis, estão alteradas. A sensação de que tudo é possível é fundamental para que se possa compreender que não 
há centralidade dos signos, mas um deslocamento através das fronteiras do tempo e do espaço. A noção de flexibilidade é o conceito-chave para se entender que a mudança discursiva e social cria novas possibilidades, mas também afeta as práticas sociodiscursivas, as relações sociais e as identidades existentes.

O estudo da mudança sociodiscursiva deve se centrar tanto no evento discursivo (instância de uso da linguagem analisada como texto, prática discursiva e prática social) quanto no momento institucional das ordens do discurso.

Disso decorre que as mudanças no sistema de gêneros discursivos podem gerar efeitos e conseqüências nas configurações dos outros elementos. É por esse motivo que Fairclough (1992) considera gênero discursivo como o foco potencial de mudança e criatividade dentro da sociedade contemporânea. Primeiramente, porque é um constituinte da ordem do discurso; em segundo lugar, porque, além de se inscrever na história, faz com que a história se inscreva nele. Gênero discursivo é um elemento integrador de outros elementos sociodiscursivos, constituindo identidades sociais, relações sociais, crenças e valores. Em outras palavras, quando interagimos com o outro, nós o fazemos através da produção de gêneros discursivos inscritos na história política da sociedade.

Fairclough (1989, p. 164), ao discutir sobre o discurso na mudança social, assevera que as "imposições da economia e do estado sobre a vida têm resultado em problemas e crises da identidade social [...]", mudando o foco ideológico da produção econômica para o consumo e transformando, assim, a esfera cultural. Argumenta ainda que as ordens do discurso estabelecidas hoje pelas instituições são as do consumo e da publicidade, as da tecnologia e as da burocracia.

\section{O HIBRIDISMO E O GÊNERO DISCURSIVO}

Discutir a relação entre gênero discursivo, hibridismo e mudança social sem se reportar às idéias de Bakhtin é fazer uma leitura negligente de tal relação. Em Marxismo e Filosofia da 
Linguagem, Bakhtin (1992) argumenta sobre o caráter dinâmico e tenso da noção de contexto, implicando, posteriormente, a idéia de que os gêneros discursivos estão em constante transformação sob o olhar cuidadoso de uma comunidade interpretativa. Já em Estética da criação verbal, Bakhtin (2000, p. 285) pontua que "as mudanças históricas dos estilos da língua são indissociáveis das mudanças que se efetuam nos gêneros do discurso". Para este teórico russo, são os gêneros discursivos os responsáveis pelas mudanças, mesmo que sensíveis, entre a historicidade social e a história da língua.

É nesse contexto que Bakhtin (1986, p. 180) afirma que a linguagem entra na vida dos participantes e vice-versa já que "cada época e cada grupo social tem seu repertório de formas do discurso na comunicação sócio-ideológica”. Observa-se hoje, por exemplo, o surgimento de gêneros midiáticos enfocando problemas sociais, como os programas que discutem e mostram atos de violência e criminalidade - Cidade Alerta e Linha Direta. Tais gêneros midiáticos inserem-se no panorama histórico-cultural, atendendo aos objetivos mercadológicos e satisfazendo os desejos de uma audiência ávida por notícias sobre crime e violência.

Corroborando essa historicidade latente na atividade humana comunicativa, Kristeva (1986, p. 39) argumenta que "a inserção da história (sociedade) em um texto e deste na história" revela claramente esse trabalho de absorção e recriação de textos envolvendo textos do passado, ou seja, textos da própria vida em sociedade.

Confirmando essa tese, Todorov (1980, p. 50) assume que "cada época tem seu próprio sistema de gêneros que está em relação com a ideologia dominante, etc. Como qualquer instituição, os gêneros evidenciam os aspectos constitutivos da sociedade a que pertence". Um exemplo disso é a produção, o consumo e a distribuição dos chamados gêneros digitais (blogs, e-mails, links, chats) em conseqüência da entrada e do avanço dos computadores, principalmente, da rede mundial - Internet.

Isso aponta para uma relação entre mudança social e mudança lingüística: "[...] deve-se desenvolver uma história especial dos 
gêneros de fala que reflita mais direta, clara e flexivelmente todas as mudanças da vida social" (BAKHTIN, 1986, p. 123). É através das falas dos participantes, de sua visão de mundo, dos seus estilos, da escolha do gênero discursivo, da natureza do evento comunicativo, dos elementos semânticos que, segundo o autor, os gêneros discursivos se tornam livres, plásticos e móveis. Exemplo disso é o gênero discursivo midiático "colunismo social", que traz informações sobre celebridades nacionais e internacionais; um mix comunicativo de entretenimento e informação. Esse tipo de gênero já existia em produções impressas, atendendo a um público-consumidor limitado já que a sua distribuição dependia da compra dos exemplares pelos leitores. Com o novo formato, quem possui televisão já tem acesso a tal gênero, ampliando, assim, sua distribuição. O surgimento do gênero televisual "colunismo social" reflete claramente o comportamento sociocultural de uma sociedade que procura se entreter com fatos privados publicizados de celebridades.

Convém sublinhar que, sendo a linguagem produto da interação social, tomando a forma de enunciados concretos, as mudanças nos recursos lingüísticos interferirão nas mudanças dos gêneros discursivos, implicando uma total dependência do contexto e da linguagem em uso, como determinantes do caráter flexível e relativamente estável dos gêneros discursivos.

Podemos começar por dizer que os gêneros discursivos são "movediços" porque dependem da situação comunicativa, da posição social e das relações sociais dos participantes no evento comunicativo.

Outro ponto a ser destacado nestes estudos é a ênfase no social. Bakhtin (1986) considera que o gênero da fala não é a forma da linguagem, mas uma forma típica concretizada de linguagem que é assimilada, transformada e indexada pelas práticas sociais. Para compreender tal movimento, Bakhtin (1986, p. 132) argumenta que "cada gênero de fala em cada área de comunicação de fala tem sua própria concepção típica de endereçamento, e isto define um gênero". Se a realização de tal fenômeno lingüístico-discursivo 
encontra-se atravessada pela dependência dos diferentes níveis de organização do social, então há uma relação determinada do sujeito com a história.

Essas considerações me parecem importantes, dado que, nos estudos bakhtinianos, já se previa uma relação indissolúvel entre o texto e a memória intertextual/interdiscuriva baseada nas interações verbais dialógicas. Melhor dizendo, é a condição dialógica da realização lingüística que reestrutura e /ou recontextualiza discursos, gêneros discursivos e textos sob a forma de produções intertextuais e interdiscursivas. Essa tese parece se inscrever nas várias propostas que têm sido feitas, por parte de pesquisadores não só da área da Análise de Gêneros (MILLER, 1984; SWALES, 1990; BHATIA, 1994; BERKENKOTTER e HUCKIN, 1995) como também da Análise de Discurso Crítica (FAIRCLOUGH, 1992; KRESS, 1989).

Entre essas propostas, uma referência teórica bastante difundida nos estudos sobre gênero discursivo são os estudos sobre construcionismo social, reivindicado e debatido por Miller (1984). Sublinha-se, inicialmente, que a re-interpretação de Bakhtin (1986) aqui discutida se inscreve, de alguma forma, no posicionamento epistemológico de Miller (1984), constituindo um prolongamento daquele programa.

Miller (1984) argumenta que tanto os gêneros discursivos orais como os escritos são "ações sociais tipificadas", assumidas através de um processo de contextualização, resultado da interação verbal sociocultural entre os atores sociais. A autora sustenta que essas ações sociais tipificadas são marcadas e assinaladas nos textos por meio de processos intertextuais e interdiscursivos, concebendo, assim, linguagem como ação social, e a construção do mundo como resultado desta.

Nesse enquadramento, Miller (1984) insiste que a comunidade tem um estoque estável de conhecimentos, que pode ser mudado, se os participantes identificarem uma nova situação que requeira uma nova resposta retórica. Essa nova criação envolve, assim, a formação de novos gêneros discursivos que são construídos através de 
modelos de intertexto e interdiscurso - conceitos adotados de Bakhtin (1984) e, posteriormente, difundidos por Kristeva (1986) e Pêcheux (1975). Esse reconhecimento da situação-tipo comunicativa, já indexada e precedida, envolve não só o tipo de situação, mas também a retórica e a relação interacional entre os participantes.

Fairclough (1989, 1992) adotou uma abordagem de gênero discursivo bastante próxima às de Bakhtin (1986), Miller (1984) e Kristeva (1986), usando gênero discursivo como tipos socialmente ratificados de atividades lingüísticas que especificam posições para sujeitos e argumentando, ainda, que discursos e gêneros discursivos jogam com regras recursivas que não só afetam as mudanças sociais como são afetados por elas.

Fairclough (2001b, p. 161) propõe uma visão de gênero discursivo essencialmente bakhtiniana:

[...] um conjunto de convenções relativamente estável que é associado com, e parcialmente representa, um tipo de atividade socialmente aprovado, como a conversa informal, a compra de produtos em uma loja [...].

Essa visão bakhtiniana respalda a idéia de que gênero discursivo, antes de ser um texto, é processo de produção, distribuição e consumo, sendo também um instrumento potencial de mudança social e de subversão.

Nessa perspectiva, gênero discursivo está associado a um tipo de atividade particular que se especifica em termos de uma seqüência estruturada de ações sociais, realizada por sujeitos que ocupam posições sociais constituídas e reconhecidas por situaçõestipo. Por exemplo, um evento comunicativo como a tomada de depoimento numa delegacia envolve o depoente, o encarregado da justiça e o escrevente como sujeitos designados para a seqüência de ações que serão construídas e desenvolvidas.

Dentro de um quadro de estudos críticos do discurso, Fairclough $(1989,1992)$ postula que o sistema de gênero discursivo adotado por uma determinada sociedade num período histórico determina as 
combinações e articulações dos tipos de discursos que ocorrem. Exemplifica essa afirmação a capa do documento oficial emitido pelo convênio de seguro da DPVAT/99 para que o contribuinte pagasse o seguro do carro. Aspecto interessante no texto é que, além de ele apresentar uma configuração icônica de fôlder publicitário (carro tomando sol e bebendo um drink embaixo de uma barraca), traz também um gênero do tipo slogan publicitário - Quem paga seguro segue tranqüilo. Isso configura não só um hibridismo entre um documento oficial e um gênero autopromocional, mas também e, principalmente, evidencia uma forte tendência discursiva autopromocional e tecnocrática imposta pelos imperativos econômicos, questões próprias deste contexto sócio-histórico de modernidade tardia.

O gênero discursivo realiza o elo entre a prática social e o texto, estabelecendo relações entre as instâncias de produção, distribuição e consumo dos textos. Essa conexão se dá por meio de convenções partilhadas, em situações sociais, através de comunidades discursivas que possuem objetivos e propósitos comuns.

Justificando tal posicionamento, Fairclough (2001b, p. 161) afirma que é de interesse da relação entre mudança social e discurso "a mudança no sistema de gêneros e seus efeitos sobre as configurações de outros elementos", porque parte-se da tese de que as mudanças nas práticas discursivas integram um amplo processo de mudança social e cultural, assim como as mudanças sociais e culturais reestruturam as práticas discursivas.

Essa recontextualização e articulação das ordens do discurso é realizada no texto, através dos processos de intertextualidade e interdiscursividade, por meio de alguns elementos, quais sejam: tipos de discursos, gêneros discursivos, estilos, tipos de atividades e voz.

O gênero discursivo telenovela, por exemplo, traz notadamente hoje uma configuração híbrida, tendo dois propósitos comunicativos: o de entretenimento e o educativo. Obviamente tal composição comunicativa procura atender não só aos interesses da audiência, mas também aos propósitos político-econômicos das emissoras e dos anunciantes. Pode-se postular que tal composição híbrida seja o 
resultado de uma reestruturação das práticas discursivas em função de uma conscientização da força midiática das novelas pelo viés ficção/ realidade. Ou seja, através de depoimentos reais e dados científicos reportados, discutem-se problemas emergentes na sociedade contemporânea pelo viés do discurso ficcional, obtendo assim uma maior audiência.

Dessa forma, são os gêneros discursivos que determinam as combinações e configurações que ocorrem nos outros elementos. Numa ordem do discurso jurídico-política ambiental pode-se encontrar uma combinação particular de gêneros discursivos (relatórios, processos, audiências públicas) que se relacionam de formas distintas com diferentes estilos (formal ou informal), tipos de discursos e vozes. O consumo do gênero relatório, por exemplo, pode ser coletivo ou individual, ou ainda ter uma distribuição individual e uma produção coletiva, bem como possuir características mais formais do que informais. Pode ser produzido com um cunho mais argumentativo e descritivo que narrativo.

Para Fairclough (1995, p. 14), não se pode conceber gêneros discursivos apenas como uma estrutura esquemática, mas como "[...] uma forma aprovada socialmente de uso da linguagem em conexão com um tipo particular de atividade social". Gênero do discurso, então, se constitui numa relação dialética entre estrutura e ação, entre convenção e evento.

Chouliaraki e Fairclough (1999) apontam que gênero discursivo, discurso e voz podem se realizar juntos numa mesma ordem do discurso, e que os textos que os realizam podem auxiliar em suas possíveis mudanças e mixagens. O certo é que gênero discursivo é compreendido como um tipo de linguagem associado a uma atividade social particular; discurso é um tipo de linguagem usado para construir algum assunto ou aspecto da realidade de um modo particular (Cf. FOUCAULT, 1979); e voz se caracteriza como um tipo de linguagem empregado por um grupo social, associado a uma identidade particular.

Então, a forma como um tipo de discurso se encaixa em um tipo de gênero discursivo é um modo de estabelecer e especificar 
sua distribuição, ou seja, a forma como os textos realizam as cadeias intertextuais e interdiscursivas depende da maneira como os diversos tipos de discursos, estilos e vozes variam e se combinam em certos tipos de gêneros discursivos, levando em conta suas redes de distribuição. Fairclough (1992) admite que essas cadeias tornam-se linhas de tensão e mudança, pois os canais pelos quais os tipos de textos são colonizados e investidos e suas relações com as outras cadeias intertextuais é que garantem a contestação, a luta. É claro que essas linhas de tensão marcam também a sujeição e a subordinação, muitas vezes, da produção dos gêneros discursivos aos imperativos econômicos.

Exemplo disso é a transformação do gênero discursivo cordel tradicional em cordéis do tipo contemporâneo. O cordel tradicional era feito do povo para o povo, indagando sobre as crenças e os valores do povo nordestino; o cordel hoje é produzido, muitas vezes, por jornalistas, que o distribuem na rede, retratando questões políticas tanto nacionais quanto internacionais (RESENDE \& GOMES, 2003).

Fairclough (2001b, p. 96) admite ainda que "os limites entre os elementos podem ser linhas de tensão”, ou seja, se os discursos e gêneros discursivos articulados têm ordens sociais diferentes, os seus limites tornam-se foco de contestação. Essas tensões, como foi dito, marcam a instabilidade entre os gêneros do discurso, "tornando-os abertos à interpelação de instituições geradoras de discursos em disputa ou em contínuo estado de tensão" (PAGANO, 2001, p. 100).

Chouliaraki e Fairclough (1999) partem da noção de que os textos não são apenas ativos na organização das relações sociais que eles medeiam, mas também são originalmente híbridos. A tese central destes autores é que "texto ativo é também um texto híbrido e que entender esse hibridismo é a chave para entender a atividade" (CHOULIARAKI e FAIRCLOUGH, 1999, p. 57). O hibridismo mostrará, então, como as cadeias de ordens do discurso são criativamente redesenhadas e articuladas dentro da posição que ocupam.

Chouliaraki e Fairclough (1999, p. 116) consideram então que 
gêneros e discursos podem tornar-se desencaixados de ordens do discurso particulares e circular como elementos livres e flutuantes capazes de serem articulados juntos de novas maneiras, como a manifestação de processos de mudança social no discurso.

O destaque dado por Fairclough (1995) à construção de gêneros discursivos híbridos nas sociedades contemporâneas marcadas pelos efeitos das formas de globalização e da modernidade tardia ressalta a emergência de novos gêneros discursivos. É o caso dos gêneros digitais e hipertextos, que mesclam a oralidade à escrita, efetuando relações sociocomunicativas mais simples e econômicas.

Um tipo de gênero discursivo exemplar desta relação entre mudança social e hibridismo é o que denomino gênero informepublicitário. Tal gênero revela-se híbrido, a princípio, por atender a dois propósitos comunicativos distintos: informar e vender, ocasionando uma produção comunicativa ambivalente e conflituosa, já que seria uma publicidade mascarada de notícia (GOMES, 2003). Pode-se dizer que tal gênero híbrido é uma conseqüência do contexto sócio-histórico pós-moderno; uma era caracterizada pela inserção do consumo, dos imperativos econômicos e dos avanços tecnológicos na produção dos sistemas de gêneros.

Um discurso que emerge no contexto da modernidade tardia é o autopromocional, que está presente em variadas práticas discursivas, determinado pelos interesses econômicos e mercadológicos desta nova sociedade contemporânea. Fairclough (2001a), por exemplo, ao analisar a mercadologização das práticas discursivas das universidades públicas na Grã-Bretanha, argumenta que as práticas discursivas da educação superior estão colonizadas pelo discurso promocional, ou da indústria dos bens de consumo.

Analisando o fôlder do vestibular de uma instituição de ensino superior no Brasil, percebe-se claramente características dessa função comunicativa autopromocional. O texto do fôlder evidencia uma vOZ institucional entrecruzada a uma voz tecnocrática, através da seleção dos seguintes léxicos: a instituição $\mathrm{x}$ 
manutenção de programas de investigação. Com impactos diversos na economia nacional, procura oferecer $\mathrm{x}$ uma oportunidade de complementação da formação, comprometimento de x com a responsabilidade social, sem perder de vista o constante treinamento, o repasse de conhecimentos aqui gerados.

É claro que o propósito comunicativo do gênero fôlder é chamar a atenção dos vestibulandos para a instituição, destacando o que ela tem de melhor para lhe oferecer. A questão é que, ao utilizar tal gênero autopromocional, a instituição estabelece-se sob o aspecto de uma identidade investidora, que propõe uma variedade de serviços, concebendo os vestibulandos, futuros alunos, como investidores potenciais, clientes. Disso decorre que a instituição, responsável pela construção e circulação do conhecimento, é atravessada por uma identidade promocional, geradora de bens de consumo e serviços.

Resgatando assim concepções de Miller, Bakhtin, Kristeva, Pêcheux e Foucault, Chouliaraki \& Fairclough (1999) argumentam que as análises das práticas discursivas na modernidade tardia perpassam pelas seguintes categorias: situação-tipo social recorrente, ação social, gênero discursivo, ordem do discurso, interdiscurso e intertexto.

Neste ponto, reconhece-se junto a Miller (1984), Bakhtin (1986), Fairclough (1989, 1992, 1995) e Chouliaraki \& Fairclough (1999) que a abordagem de gênero discursivo como ação social que constitui e é constituído pelo social, acarretando possíveis mudanças sócio-históricas, implica que um texto/discurso não pode ser inferido diretamente da materialidade lingüística, sem que seja inserido no social, já que é construído, ativo, e não um processo fixo, estável e passivo. Pode-se argumentar, então, que formas prototípicas particulares, recorrentes da linguagem em uso, constituem e são constituídas também por dimensões históricas.

Nessa perspectiva de estudo, Berkenkotter e Huckin (1995) investigam, em seus estudos, como a evolução do gênero discursivo pode indicar a estruturação e o status/poder de uma comunidade científica. O ponto forte desse trabalho analítico está na forma como os teóricos chamam a atenção para o encaixamento do discurso científico ao discurso da "cultura promocional de consumo". 
Se o artigo científico no gênero jornalístico está se orientando para um gênero promocional, de consumo, então, está realmente ocorrendo uma reestruturação entre duas ordens do discurso: a científica e a promocional, gerando um gênero discursivo híbrido. Discutindo essa questão, Fairclough (2001b, p. 151) admite que "textos do tipo informação-e-publicidade, com fins de vender e informar, são comuns em várias ordens do discurso institucionais nas sociedades contemporâneas", pois está ocorrendo um movimento colonizador, pós-industrial, do gênero publicidade em vários domínios sociais, produzindo gêneros híbridos, a partir de reestruturações de ordens do discurso.

A emergência de construção de novos gêneros e estilos discursivos deve-se, primeiramente, às novas conversações e interações sociais pautadas nas atuais formas tecnológicas decorrentes do processo de globalização e dos discursos na modernidade tardia que afetam as práticas sociais e discursivas.

Talvez não seja novidade a idéia de que a linguagem e, por conseqüência, o sistema de gêneros discursivos seriam os instrumentos potenciais de mudança social, que reverteriam a ordem de perversidade que grassa pelo mundo. Talvez ainda seja uma construção discursiva ingênua de que a linguagem seja a responsável por tal reversão, mas acredito também que só através da criação de um projeto antihegemônico que ressalte a conscientização crítica da linguagem é que poderemos tentar explicitar as naturalizações discursivas da mídia-mercado.

\section{REFERÊNCIAS BIBLIOGRÁFICAS}

BAKHTIN, M. Problems of Dostoevsky's poetics. Manchester: Manchester University Press, 1984.

BAKHTIN, M. The problem of speech genres. In: JAWORSKI, A; COUPLAND, N. (Ed.). The discourse reader. London \& New York: Routledge, 1986.

BAKHTIN, M. (Volochínov). Marxismo e Filosofia da Linguagem. São Paulo: Hucitec, 1992. 
BAKHTIN, M. Estética da criação verbal. São Paulo: Martins Fontes, 2000.

BERKENKOTTER, C.; HUCKIN, T. Genre knowledge in disciplinary communication: cognition, culture e power. New Jersey: Lawrence Erbaum Associates, 1995.

BHATIA, V. Analysing Genre: language use in professional settings. New York: Longman, 1994.

CHOULIARAKI, L.; FAIRCLOUGH, N. Discourse in late modernity. Endiburgh: Endiburgh University Press, 1999.

FAIRCLOUGH, N. Language and power. London: Longamn, 1989.

. Discourse and social change. Cambridge Polity Press, 1992.

. Media Discourse. London: Edward Arnold, 1995.

. Dialogue in the public sphere. In: Discourse and Social life. Longman, Tearson Education, 1998.

- A análise crítica do discurso e a mercantilização do discurso público: as universidades. In: MAGALHÃES,C. (Org.). Reflexões sobre a análise crítica do discurso. Belo Horizonte: Editora UFMG, 2001a.

. Discurso e mudança social. Tradução (Org.). Izabel Magalhães. Brasília: UNB, 2001b.

FOUCAUlT, M. A arqueologia do saber. 2. ed. Rio de Janeiro: ForenseUniversitária, 1979.

GIDDENS, A. As conseqüências da modernidade. São Paulo: Editora UNESP, 1991.

GOMES, M. C. A. A construção sociopolitica do gênero informe publicitário ambiental, 2003. (No prelo)

HARVEY, D. Condição pós-moderna: uma pesquisa sobre as origens da mudança cultural. São Paulo: Loyola, 1989.

KRESS, G. Genre as social process. In: COPE, B.; KALANTZIS (Ed.). The power of literacy: a genre approach do teaching writing. London: The Falmer Press, 1989.

KRISTEVA, J. The kristeva reader. Oxford: Blackwell, 1986.

MILLER, C. Genre as social action. Quartely Journal of Speech 70, p.151-167, 1984.

PAGANO, A. Gêneros híbridos. In: MAGALHÃES, C. M. Reflexões sobre a análise crítica do discurso. Belo Horizonte: FALE/UFMG, 2001.

PÊCHEUX, M. Les vérités de la palice. Paris: Maspero, 1975. 
REZENDE, V.; GOMES, M.C.A. O cordel tradicional e sua função na luta hegemônica: um estudo de caso. Papéis: Revista Letras. Campo Grande, MS. v.7, n.13, p.30-39, jan/jun.2003.

SWALES, J. Genre Analysis: English in academic and research settings. Cambridge University Press, 1990.

TODOROV, T. Os gêneros do discurso. São Paulo: Martins Fontes, 1980. 